\title{
Adaptation of A Computer Assisted System for Simultaneous Temperature Measurement at Multiple Anatomical Locations for Surgical Experiments
}

\author{
Markus Puchinger*1, Ingeborg Keeling ${ }^{1}$ and Philip Samer ${ }^{2}$ \\ ${ }^{1}$ Department of Surgery Medical University of Graz Graz, Austria \\ ${ }^{2}$ Department of Electronics, Higher Technical School and Research Center Pinkafeld Pinkafeld, Austria \\ *Corresponding author: Markus Puchinger, Department of Surgery, Medical University of Graz, Graz, Austria
}

\section{ARTICLE INFO}

Received: 慧 August 03, 2020

Published: 仹 August 11, 2020

Citation: Markus Puchinger, Ingeborg Keeling, Philip Samer. Adaptation of A Computer Assisted System for Simultaneous Temperature Measurement at Multiple Anatomical Locations for Surgical Experiments. Biomed J Sci \& Tech Res 29(3)-2020. BJSTR. MS.ID.004808.
ABSTRACT

In surgery it is frequently of interest to measure different parameters simultaneously. The goal of this work was to find an optimal system for this purpose and to build up a multichannel temperature measuring system. We selected a highly flexible system, which also provides Ethernet compatibility in conjunction with relatively easy development of specific software. Specifically, the temperature measurement component was realized with Pt-1000 sensors, which were connected to the base in four-wire link. First tests after calibration showed stable and reproducible values over a long time period. The system works well, and it can be adapted in a way to allow measurements of further physical parameters in the near future.

Keywords: Multichannel-Measurement; Temperature-Measurement; SurgicalExperiments; Physiological-Experiments

\section{Introduction}

In the context of surgical and physiological experiments it is often necessary to perform measurement of a certain number of physical parameters synchronously. A further challenge is the data acquisition of a single parameter and of possible relationships between each other. Therefore, it seems important to develop measuring equipment which provides sampling of several channels and simultaneous storage. The first goal was to provide a system which is able to measure the temperature at two or more different locations simultaneously.

\section{Material and Methods}

As base hardware we tested a network-compatible measuring computer, manufactured by the company National Instruments, Austin, Texas, USA. We also examined the data acquisition software "LabVIEW ${ }^{\circledR ”, ~ w h i c h ~ i s ~ p r o v i d e d ~ b y ~ t h e ~ s a m e ~ c o m p a n y . ~ B o t h ~ b u i l d ~ u p ~}$ an industry standard within technical industrial research application. Furthermore, experiments in biomedical research were realized [1-2]. In a clinical environment it provides certain advantages to have all collected data available on a data network. Therefore, we chose NI cDAQ-9188 ${ }^{\circledR}$ (Figures $1 \& 2$ ), which is equipped with a LAN connector (most essential features see Table 1).

Table 1: Features of the Ni Cdaq-9188®

\begin{tabular}{|c|c|c|}
\hline \multirow{2}{*}{ NI cDAQ- 9188® } & \multicolumn{2}{|c|}{ Features of the DAQ Device } \\
\cline { 2 - 3 } & Basic features & Compatibility \\
\hline & $\begin{array}{c}\text { Chassis with 8 slots for } \\
\text { modules }\end{array}$ & 256 channels \\
\hline & $\begin{array}{c}\text { More than 50 modules } \\
\text { available (Figure 2) }\end{array}$ & $\begin{array}{c}\text { Ethernet connec- } \\
\text { tora }\end{array}$ \\
\hline
\end{tabular}

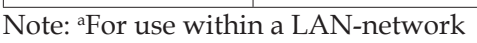

\section{Temperature Sensors}

If a two-wire link would be used for the temperature measurement (Figure 3), the temperature dependence of the sensor connectors would influence the accuracy of the overall system in a negative way. Therefore, in order to provide the best results with regard to an optimal accuracy, we used high quality Pt-1000 sensors, which were connected to the base using a four-wire link (Figure 4) [3]. 


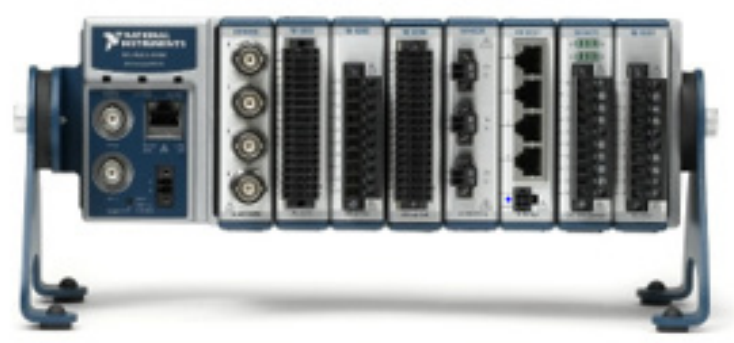

Figure 1: Basic hardware: NI cDAQ-9188®, National Instruments, Austin, Texas, USA.

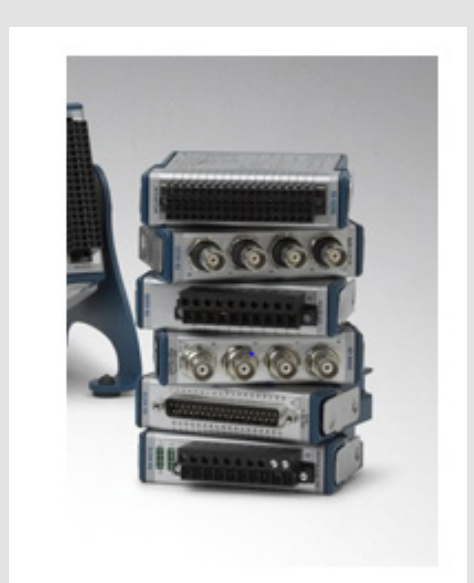

Figure 2: Modules for NI cDAQ-9188® for special applications, available at the manufacturer.

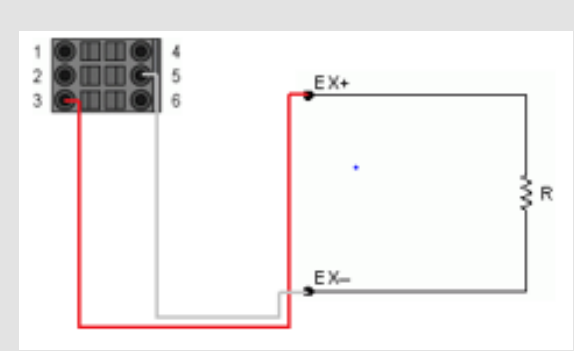

Figure 3: Two-wire link for the temperature measurement.

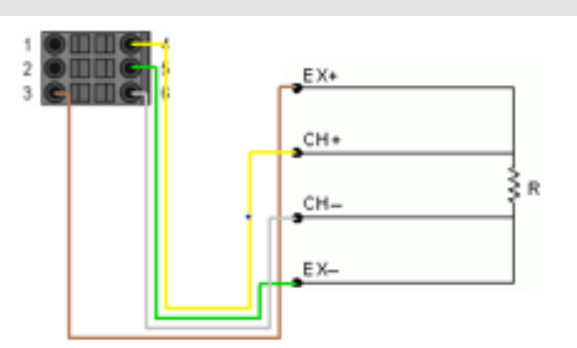

Figure 4: Pt-1000 temperature sensors are connected to the base using a four- wire link.

\section{Software Design}

Based on the data acquisition software "LabVIEW ${ }^{\circledR ”}$ we built up an user interface with three channels. "LabVIEW ${ }^{\circledR ”}$ is a graphical programming software, which allows to realize quick and simple software solutions for specific purposes [4]. The package contains numerous predefined commands and routines. Our setting for three parallel channels allows the measurement of the temperatures on three different anatomical locations simultaneously (Figures 5 \& 6). The DAQ-assistant provides the "interface" to the hardware. Its application is very simple, because it is only necessary to select the appropriate values within a predefined setting (Figure 7). An individually designed mathematical formula can be directly inserted into the predefined software component formula (Figure 8). For further graphical presentation of the data it is necessary to predefine an array for each temperature channel. Oder: Graphical presentation of the data is realized by predefining an array for each temperature channel. For the calculation of the temperature of each sensor, based on the resistance, we used (2) as a result of (1), in which $\alpha$ n $(\alpha 1, \alpha 2, \alpha 3)$ was calculated on the basis of a calibration process for each of the three probes separately (3).

$$
\begin{aligned}
& R_{(T)}=R_{0} *\left(1+\alpha_{n} * T\right) \\
& T=\left(R_{(T)}-T_{0}\right) /\left(\alpha_{n} * R_{0}\right)
\end{aligned}
$$

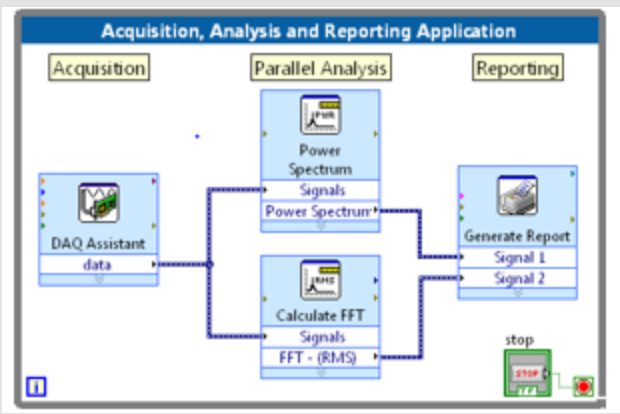

Figure 5: Graphical user interface of “LabVIEW®”.

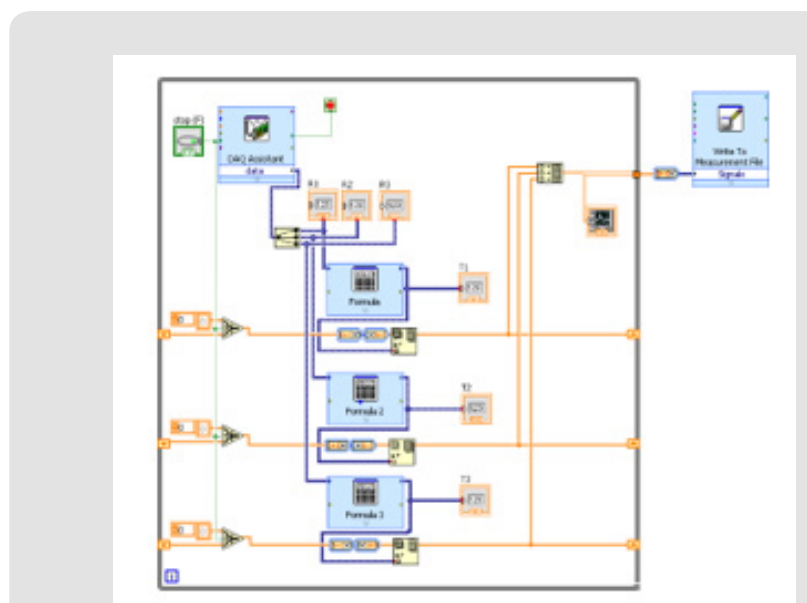

Figure 6: Setting for the simultanious measurement of three temperatures.

For the output of all three temperature values simultaneously, all three arrays are integrated within one 2D- array (Figure 9). A "VI" allows the storage of the measured values for the temperatures of all three channels at the same time (Figure 10). For the purpose 
of calibration and testing the system as a first step a provisional user interface was made/created. This interface allows the observation of the electrical resistance and of the corresponding, calculated temperature of each temperature sensor in a graphical, as well as in a quantitative presentation (Figure 11). Furthermore, especially for general technical and medical technical staff using the system, afunctional and also attractive user interface was developed in German language.

$$
\alpha_{n}=\left(R_{(T)}-T_{0}\right)\left(T^{*} R_{0}\right)
$$

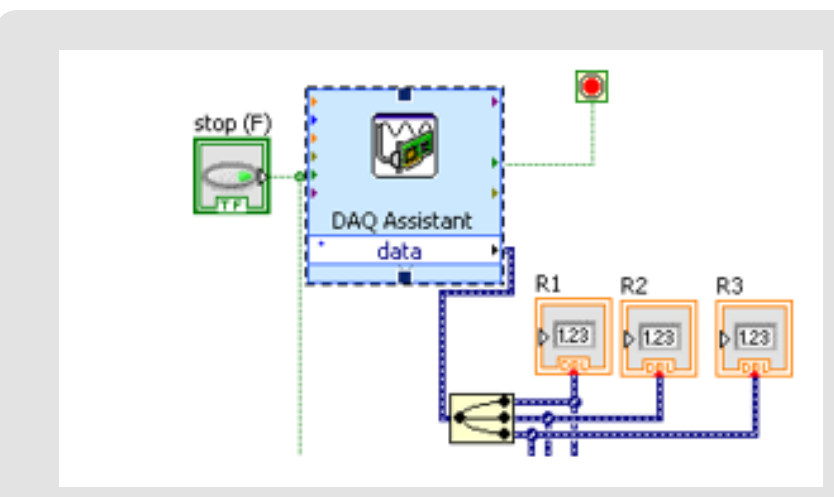

Figure 7: DAQ Assistant.

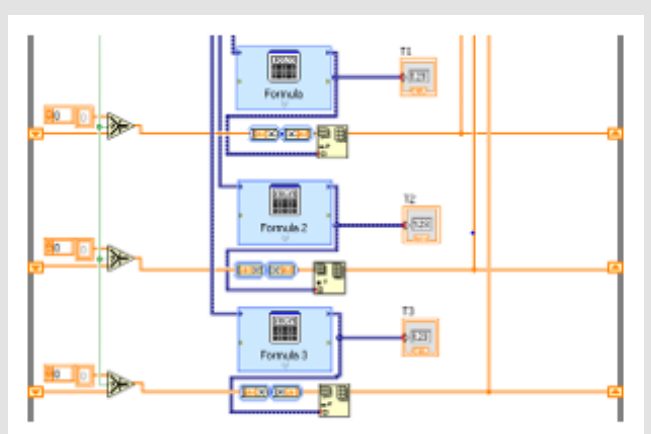

Figure 8: Calculating the temperature using der software module "formula".

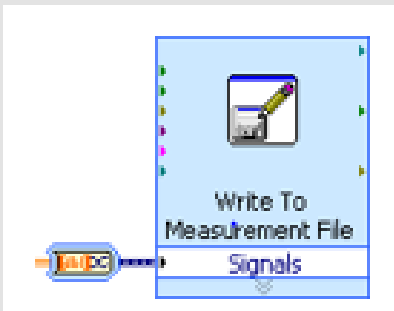

Figure 9: Digital data storage.

\section{Calibration}

The system was calibrated with the help of two calibration points. The first calibration point was realized with ice water (Figure 12), which provides a relatively stable temperature of 273.15 $\mathrm{K}\left(0.0^{\circ} \mathrm{C}\right)[4]$ The second calibration point was realized with warm water, which was heated to a slightly increased body temperature of $313.15\left(40.0^{\circ} \mathrm{C}\right)$. A high- precision fever thermometer was used in this case.

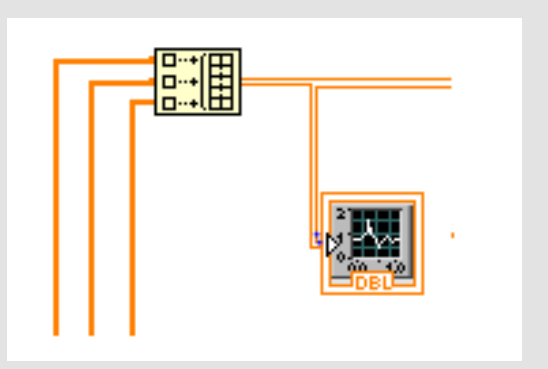

Figure 10: Data output.

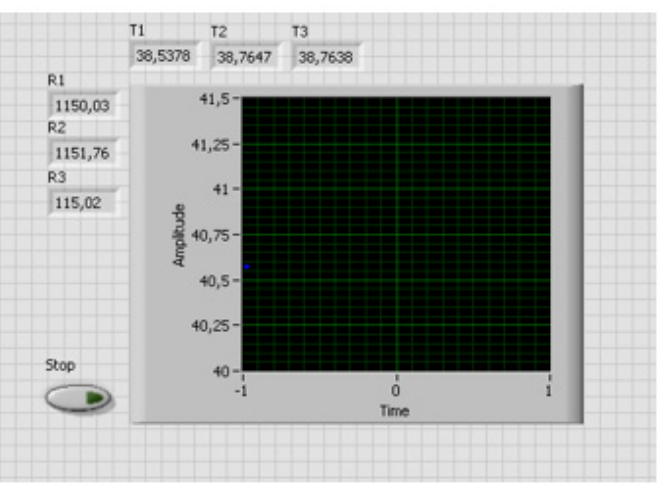

Figure 11: Grafical interface for testing and calibrating the system.

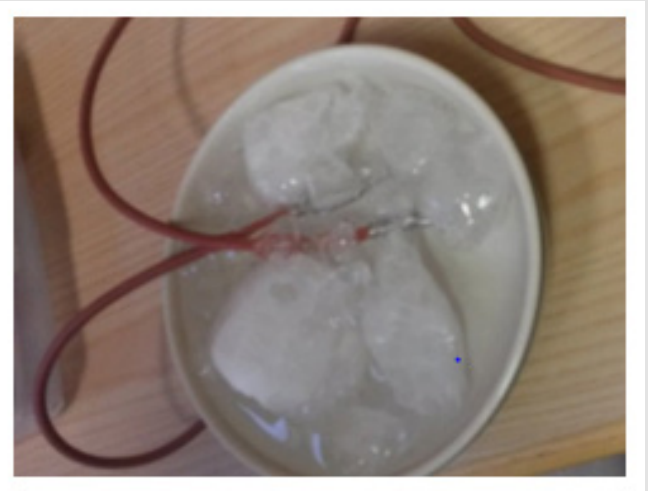

Figure 12: Calibration with ice water.

\section{Results}

The first tests of the system showed stable and reproducible values over a time of more than two hours. This arrangement allows for continuous parallel temperature measurements via three different temperature probes as well as for continuous parallel data visualization of three temperatures at the same time. All data can be stored and archived.

\section{Discussion}

Particular advantages of this device are the easy to handle „VIs“, 
provided by the manufacturer, the simple maintenance and the ability to provide new extensions. A great opportunity is the Ethernet connectivity, which allows using the system remotely via a larger distance. Measurements up to a rate of 1.6 MSamples/s allow also the detection of rapidly changing processes. The voltage range from $-15 \mathrm{~V}$ to $20 \mathrm{~V}$ also allow the use of larger sized Pt-1000 sensors, whereby the system could be extended to up to 32 channels. Since the data are automatically stored in a MS-Excel file, further data processing is quite simple. The collected data can be compared with a predefined value table for pattern recognition, perhaps useful for the detection of critical events. This first practical implementation of the system is promising, and implementation of further basic applications for the use in biomedical research seems possible within the near future. Further dimensions and physical parameters, such as pressure and volumetric flow rate, and in addition bioelectrical signals, should be examined with regard to their measurability using this system.

\section{References}

1. Martinek R, Kelnar M, Koudelka P, Vanus J, Bilik P, et al. (2016) A novel LabVIEW-based multi-channel non-invasive abdominal maternal-fetal electrocardiogram signal generator. Physiol Meas 37(2):238-256.

2. Pevtsov EF, Storozheva ZI, Proshin AT, Pevtsova EI (1982) A Hardware-and- Software System for Experimental Studies of the Acoustic Startle Response in Laboratory Rodents. Bull Exp Biol Med 160(4): 410413.

3. RP Reed: Thermoelectric Thermometry, A Functional Model from Temperature - Its Measurement and Control in Science and Industry, American Institute of Physics, NY.

4. Hafner C (2011) Calibration of temperature control and monitoring devices. Technical supplement to WHO Technical Report Series, No. 961, WHO Press, World Health Organization.

$\begin{array}{ll}\text { BIOMEDICAL } & \text { Assets of Publishing with us } \\ \text { RESEARCHES } & \text { - Global archiving of articles } \\ \text { - Immediate, unrestricted online access }\end{array}$

